\title{
Validation of ELPIS 1980-2010 baseline scenarios using the observed European Climate Assessment data set
}

\author{
Mikhail A. Semenov ${ }^{1, *}$, Scott Pilkington-Bennett ${ }^{2}$, Pierluigi Calanca ${ }^{3}$ \\ ${ }^{1}$ Computational and Systems Biology Department, and ${ }^{2}$ Biological Chemistry and Crop Protection, Rothamsted Research, \\ Harpenden, Hertfordshire AL5 2JQ, UK \\ ${ }^{3}$ Agroscope Reckenholz-Tänikon, Natural Resources and Agriculture, 8046 Zurich, Switzerland
}

\begin{abstract}
Local-scale daily climate scenarios are required for assessment of climate change impacts. ELPIS is a repository of local-scale climate scenarios for Europe, which are based on the LARS-WG weather generator and future projections from 2 multi-model ensembles, CMIP3 and EU-ENSEMBLES. In ELPIS, the site parameters for the 1980-2010 baseline scenarios were estimated by LARS-WG using daily weather from the European Crop Growth Monitoring System (CGMS) used in many European agricultural assessment studies. The objective of this paper was to compare ELPIS baseline scenarios with observed daily weather obtained independently from the European Climate Assessment (ECA) data set. Several statistical tests were used to compare distributions of climatic variables derived from ECA-observed daily weather and ELPISgenerated baseline scenarios. About $30 \%$ of selected sites have a difference in altitude of $>50 \mathrm{~m}$ compared with the CGMS grid-cell altitude that was selected to represent agricultural land within a grid-cell. Differences in altitude can explain significant Kolmogorov-Smirnov test (KS-test) results for distribution of daily temperature and in $t$-tests for temperature monthly means, because of the well-known negative correlation between temperature and elevation. For daily precipitation, the KS-test showed little difference between generated and observed data; however, the more sensitive $t$-test showed significant results for the sites where altitude differences were large. Approximately $11 \%$ of sites showed small positive or negative bias in monthly solar radiation, although $86 \%$ sites showed $>3$ significant $t$-test results for monthly means. These results can be explained by differences in conversion of sunshine hours to solar radiation used in CGMS and LARS-WG. We conclude that, considering the limitations above, ELPIS baseline scenarios are suitable for agricultural impact assessments in Europe.
\end{abstract}

KEY WORDS: Climate change $\cdot$ Impact assessment $\cdot$ Downscaling $\cdot$ LARS-WG

\section{INTRODUCTION}

Global climate models (GCMs) are state-of-the-art tools used to predict the evolution of the Earth's climate system (Meehl et al. 2007). However, the direct use of climate projections from GCMs for local assessments of climate change impacts is problematic because of the coarse spatial resolution, which results in significant errors, biases and large uncer- tainty in their output at a local scale, particularly for precipitation (Knutti 2008, Annan \& Hargreaves 2010, Iizumi et al. 2010, Eden et al. 2012). Various downscaling techniques have been developed to support local-scale impact assessments, including statistical downscaling (Wilby et al. 1998, Fowler et al. 2007, Maraun et al. 2010) and weather generators (WGs) (Wilks 1992, Barrow \& Semenov 1995, Street et al. 2009). These techniques allow for the genera- 
tion of daily local-scale climate scenarios suitable for non-linear process-based impact models, e.g. crop simulation models, which are used in impact assessments (White et al. 2011). Stochastic WGs are the most commonly used tool to generate local-scale daily climate change scenarios. Among various WGs, LARS-WG was intensively tested over diverse climate zones (Semenov et al. 1998, Qian et al. 2004, Qian et al. 2008, Semenov 2008, Street et al. 2009, Haris et al. 2010, Lazzarotto et al. 2010, Semenov et al. 2010, Luo \& Yu 2012). Overall performance of LARS-WG in representing the statistical characteristics of observed climatic variables, including extreme events, was generally good (Qian et al. 2008, Semenov 2008, Iizumi et al. 2012a). LARS-WG is available from www.rothamsted.ac.uk/mas-models/larswg. php.

LARS-WG was used recently to develop ELPIS, a repository of local-scale climate scenarios for Europe (Semenov et al. 2010, Semenov \& Stratonovitch 2010, Calanca \& Semenov in press). ELPIS consists of LARS-WG site parameters for the baseline (19802010) climate derived from the European Crop Growth Monitoring System (CGMS) data set (van der Goot 1997), and climate projections from the CMIP3 multi-model ensemble of 15 GCMs (Meehl et al. 2007) and the EU-ENSEMBLES ensemble of 9 regional climate models (van der Linden \& Mitchell 2009). LARS-WG generates future climate scenarios by altering the baseline site parameters using change factors derived from climate projections (Semenov \& Stratonovitch 2010, Iizumi et al. 2012a).

In ELPIS, site parameters for the baseline climate were derived from the CGMS gridded daily meteorological data set. CGMS was developed by the EC Joint Research Centre for agricultural assessments and yield predictions for major agricultural crops in Europe (Semenov et al. 2010). It is the core of the MARS Crop Yield Forecast System used in forecasting activities in Europe in support of the Common Agricultural Policy. Gridded daily weather in CGMS was constructed by interpolating observed daily weather from a large number of sites to a $25 \mathrm{~km}$ grid over Europe (van der Goot 1997). The number of sites used for interpolation varied between climatic variables, with over 2500 sites for precipitation and temperature and under 400 sites for sunshine hours.

The main objective of this study was to compare ELPIS-generated 1980-2010 baseline scenarios with observed daily weather for the same period 19802010 at the selected sites obtained from the European Climate Assessment (ECA) data set, which represents one of the best sources of publically available weather records in Europe (Klein Tank et al. 2002, Klok \& Klein Tank 2009). We used the KolmogorovSmirnov test (KS-test) to compare distributions of daily values, the $t$-test to compare monthly means, and the paired $t$-test for monthly means to check for a potential bias. This comparison is different from a previous comparison of ELPIS-generated baseline scenarios with the CGMS gridded daily weather, as in that study the ability of LARS-WG to reproduce diverse weather patterns in Europe was tested (Semenov et al. 2010).

\section{MATERIALS AND METHODS}

\subsection{The ELPIS baseline scenarios}

ELPIS is a repository of LARS-WG site parameters over Europe combined with climate projections from the CMIP3 and EU-ENSEMBLES multi-model ensembles. The LARS-WG site parameters were derived from the CGMS meteorological data set of observed daily weather for the period 1980-2010. Daily weather series in CGMS were interpolated to a $25 \mathrm{~km}$ grid across Europe and include precipitation, minimum and maximum temperature, and solar radiation. Daily solar radiation was estimated from daily sunshine hours using Supit's equation (Supit \& Van Kappel 1998). The interpolation procedure was selected to ensure that gridded daily values could be interpreted as typical weather over agricultural land and used in agricultural assessments (van der Goot 1997).

Semenov et al. (2010) showed that LARS-WG was able to generate synthetic weather that was statistically similar to the CGMS daily weather (Semenov et al. 2010). By using change factors derived from climate projections to perturb parameters of site distributions of climatic variables, LARS-WG can generate plausible future climate scenarios at a site with weather statistics similar to those predicted by climate models (Semenov \& Stratonovitch 2010). Climate scenarios of arbitrary length can be generated; these can be used in risk assessment and analysis of extreme events. For example, Iizumi et al. (2012b) generated a 2000-yrlong precipitation series using the LARS-WG to analyse the statistical characteristics of daily precipitation indices in Japan (Iizumi et al. 2012b). Also, Kapphan et al. (2012) generated 1000 yr of weather records to examine the weather insurance design for agricultural production (Kapphan et al. 2012). 
Table 1. Summary of statistical test results. sgn: significant; KS, Kolmogorov-Smirnov test

\begin{tabular}{|c|c|c|c|c|c|c|}
\hline & \multicolumn{5}{|c|}{ Number of sites (total number is 263) } & \multirow[b]{2}{*}{$t$-test $\operatorname{sgn}>3^{\mathrm{c}}$} \\
\hline & Bias sgn ${ }^{a}$ & Bias $>\mathrm{TR}^{\mathrm{b}}$ & $\mathrm{KS} \mathrm{sgn}>0^{\mathrm{c}}$ & $\mathrm{KS} \operatorname{sgn}>3^{\mathrm{c}}$ & $t$-test $\operatorname{sgn}>0^{\mathrm{c}}$ & \\
\hline Precipitation & 99 & 65 & 11 & 0 & 81 & 41 \\
\hline Wet series & - & - & 3 & 0 & - & - \\
\hline Dry series & - & - & 0 & 0 & - & - \\
\hline Min. temperature & 152 & 77 & 22 & 17 & 201 & 109 \\
\hline Max. temperature & 133 & 59 & 23 & 19 & 166 & 74 \\
\hline Solar radiation & 78 & 29 & 95 & 4 & 259 & 225 \\
\hline \multicolumn{7}{|c|}{ 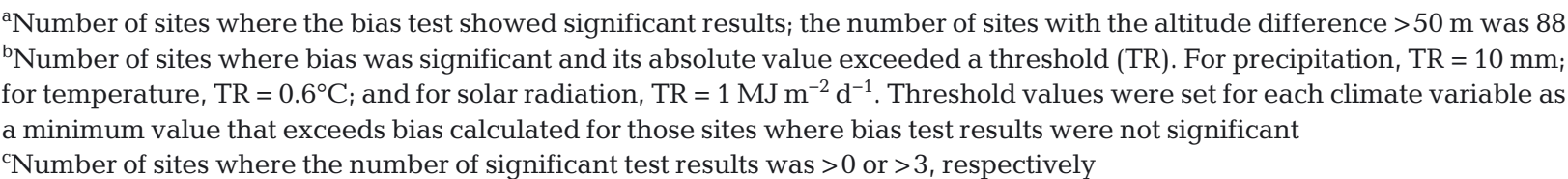 } \\
\hline
\end{tabular}

\subsection{The ECA data set of daily observations}

The ECA data set of daily weather is maintained by the Royal Netherlands Meteorological Institute (KNMI) as a part of the European Climate Assessment \& Dataset project (Klein Tank et al. 2002). ECA has been widely used for studies on climate extremes and climate change, and represents the best source of publically available daily weather for Europe (Klok \& Klein Tank 2009, Flaounas et al. 2012, van den Besselaar et al. 2012). ECA contains observations from a large number of stations located in Europe and the Mediterranean, including over 2500 sites with daily precipitation and over 1300 sites with minimum and maximum temperatures. For a smaller number of sites additional variables are available, including air pressure, cloud cover, sunshine duration, snow depth and relative humidity.

\subsection{Validation set-up}

For our study, we selected 263 sites from the ECA data set that have observed data for the period 1980-2010 and include daily precipitation, minimum and maximum temperature, and sunshine hours. Sunshine hours were converted into solar radiation using the equation described in Rietveld (1978). The locations of these sites are presented in Fig. S1 (in the Supplement at www-int-res.com/articles/suppl/ c057p001_supp.pdf).

For each selected ECA site, LARS-WG site parameters from a corresponding ELPIS grid-cell were used to generate $30 \mathrm{yr}$ of daily weather. ECAobserved and ELPIS-generated baseline weather were compared using statistical tests. The altitude of an ELPIS grid-cell represents the altitude of typical agricultural land within a grid-cell and is not necessarily equal to the altitude of the corresponding ECA site. As will be demonstrated later, this is an important consideration for explaining systematic differences in temperature and precipitation.

We used 3 statistical tests to compare observed and generated daily data. The KS-test was used to compare distribution of daily variables for each month (12 tests for each variable and for each site). The $t$-test was used to compare monthly means of climatic variables (12 tests). To check for a potential bias, we used the paired $t$-test to compare 12 monthly means of ECA-observed and ELPIS-generated daily data under the null hypothesis of no difference. For the seasonal distribution of the length of dry and wet series, the KS-test was used (4 tests for each series, wet or dry). The significance level was set to $\alpha=0.01$.

Statistical tests were based on the assumption that the observed and generated daily weather data are both random samples from existing distributions, and they tested the null hypothesis that these 2 distributions were the same. For each test we computed a p-value, which is a measure of how likely the data has occurred by chance, assuming the null hypothesis was true. Hence, a very low p-value means that the generated daily weather is unlikely to be the same as the observed weather. A large $p$-value indicates that the differences between generated and observed weather are small enough that there is insufficient evidence to reject the null hypothesis. Such tests cannot prove that the distributions are the same and the null hypothesis is true. The required closeness of the generated and observed data depends upon the application in which the generated data are used. 


\section{RESULTS AND DISCUSSION}

Table 1 presents a summary of statistical test results comparing ECA-observed and ELPIS-generated baseline scenarios.

\subsection{Analysis of precipitation}

The KS-test for seasonal distributions of dry series showed no significant results for all 263 sites. The KS-test for the seasonal distribution of wet series (4 tests per site) showed 1 significant result at 2 sites, and 2 significant results at 1 site in Spain (SID03939, Spain). The KS-test for the distribution of daily precipitation (12 tests per site) showed 1 significant result at 3 sites, and 2 significant results at 8 sites. Note, though, that even when samples come from the same
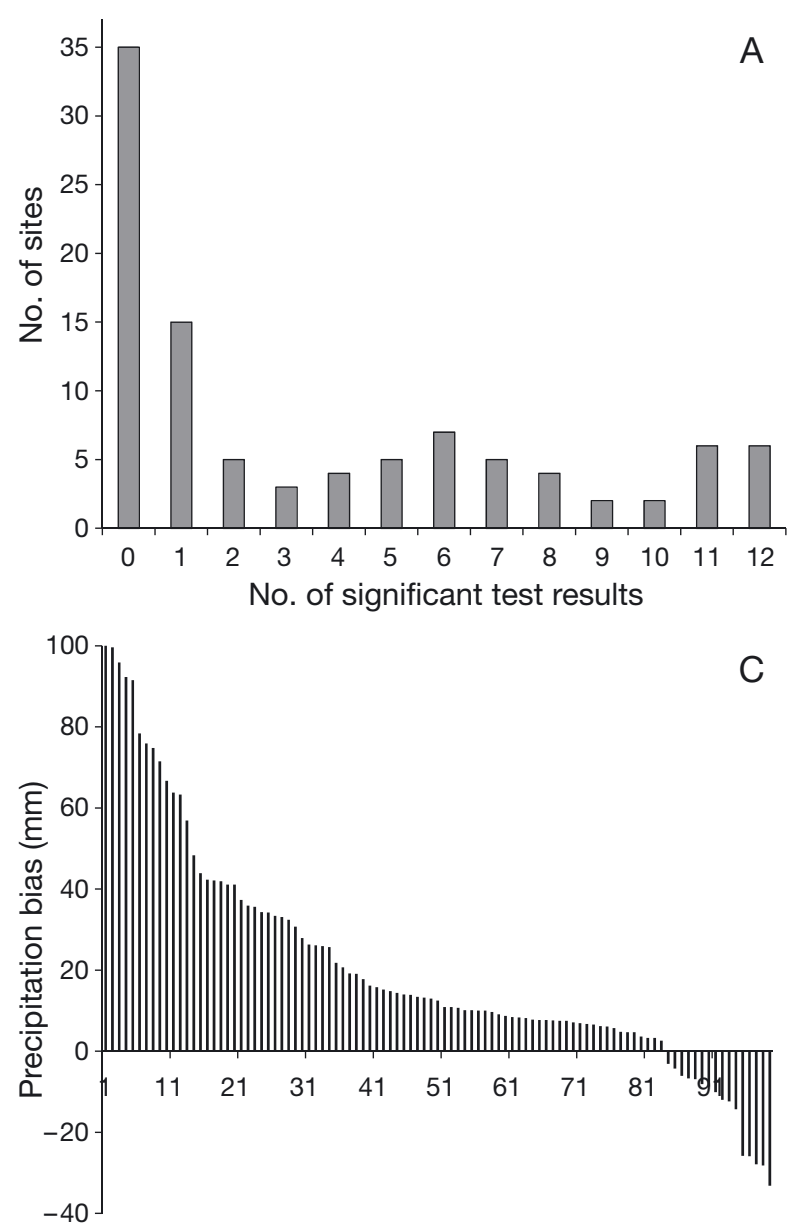

distribution, the KS-test allows for a small proportion of significant test results. For instance, when the significance level is set to 0.01 , in principle, 1 out of 100 test results could be significant. For precipitation tests, the number of significant results was in line with expectation, if we assume that precipitations are spatially and temporally independent.

Although application of the KS-test to the distribution of daily precipitation amounts (12 tests per sites) showed a relatively small number of significant results, the bias test ( 1 test per site) was more sensitive and showed significant results at 99 sites (Fig. 1A), compared with 164 sites for which the test indicated no significant bias results (Fig. 1B). For the former sites, bias values varied from 100 to $-33.2 \mathrm{~mm}$ (Fig. 1C), whereas for the latter, differences were typically of the order of a few millimeters, with only a few sites displaying absolute differences in excess of
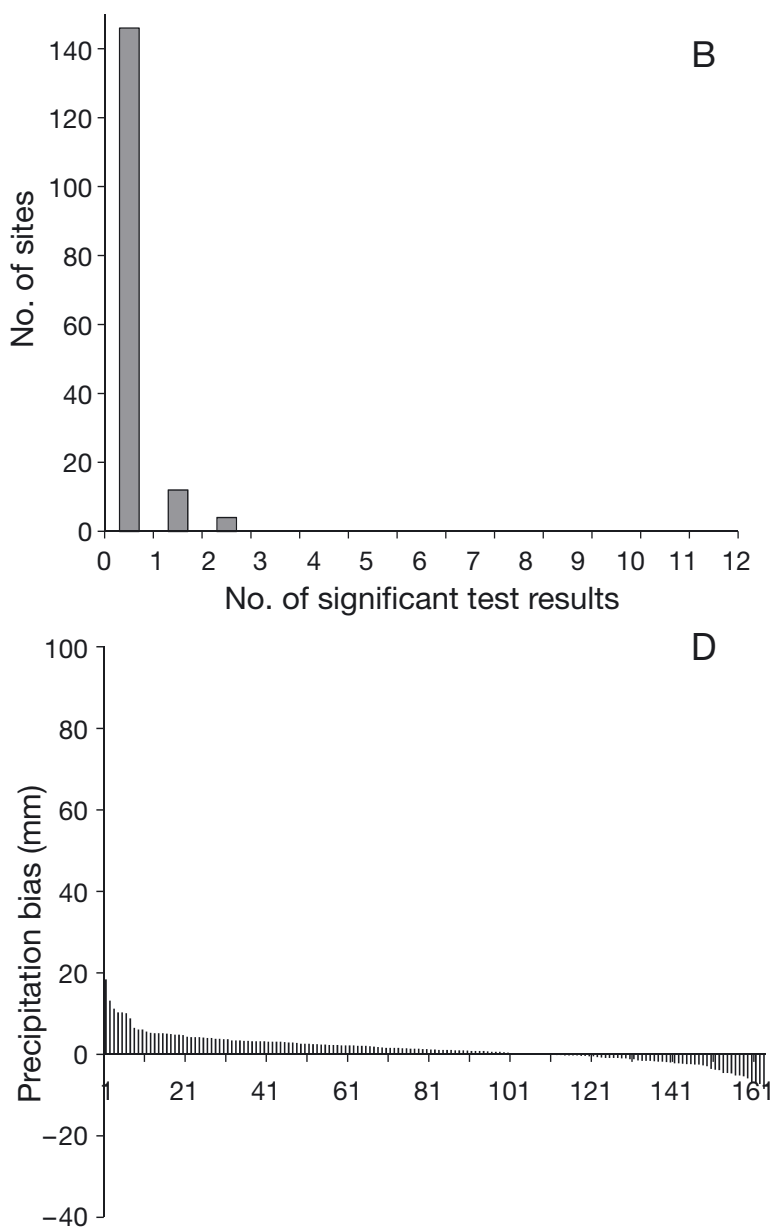

Fig. 1. (A,B) Number of sites with the exact number of significant results for $t$-tests comparing monthly mean precipitation for ECA and ELPIS: (A) sites where the test for precipitation bias showed significant results; (B) sites where test results for precipitation biases were not significant. (C,D) Precipitation bias between ECA and ELPIS calculated as the average difference in mean monthly precipitation: $(C)$ sites ordered from highest to lowest bias, where the test for precipitation bias showed significant results; (D) sites where test results for precipitation bias were not significant 

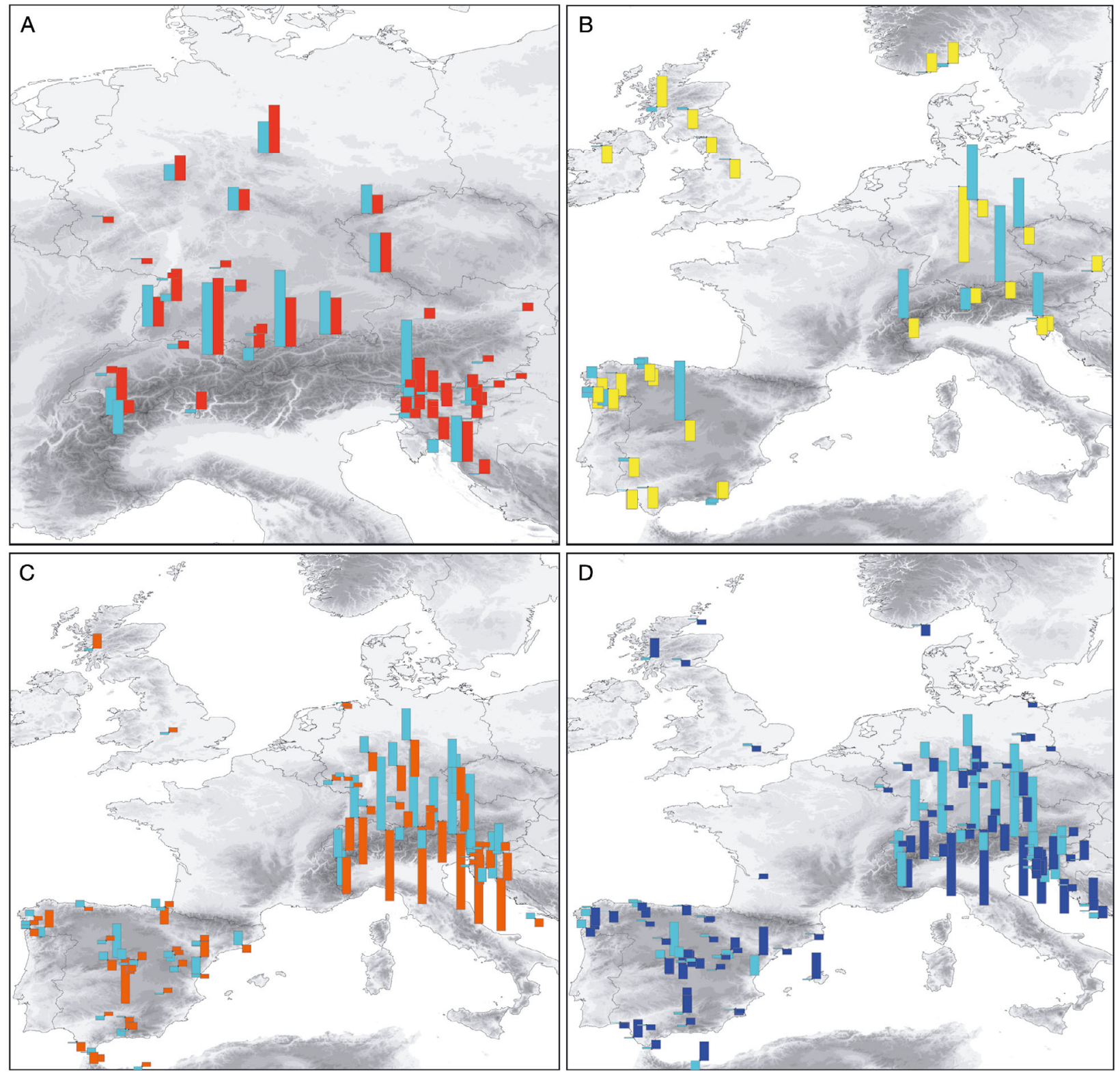

Fig. 2. Differences in altitudes (light blue bars, maximum bar height corresponds to $1900 \mathrm{~m}$ ) and biases for the sites where the bias test showed significant results and bias exceeded a threshold for (A) precipitation (red bars) (10 mm threshold, maximum bar height corresponds to $150 \mathrm{~mm}$ ); (B) solar radiation (yellow bars) (1 $\mathrm{MJ} \mathrm{m}^{-2} \mathrm{~d}^{-1}$ threshold, maximum bar height corresponds to $5 \mathrm{MJ} \mathrm{m}^{-2} \mathrm{~d}^{-1}$ ); and (C) minimum (orange bars) and (D) maximum (dark blue bars) temperatures $\left(0.6^{\circ} \mathrm{C}\right.$ threshold, maximum bar heights corresponds to 10 and $12^{\circ} \mathrm{C}$, respectively)

$10 \mathrm{~mm}$ (Fig. 1D). This latter value was therefore used as a threshold for further tests as reported in Table 1.

Fig. 2A shows precipitation bias and the altitude difference between an ECA site and a corresponding ELPIS grid-cell for locations where bias was significant and its absolute value exceeded $10 \mathrm{~mm}$. Bias was calculated as an average value between monthly means of observed and ELPIS-generated precipitation. Large precipitation biases are observed at the sites with large altitude differences. This can be explained by the
CGMS interpolation method used for precipitation. Daily precipitation for each $25 \mathrm{~km}$ grid-cell in CGMS data set was copied from the site that has the lowest site score $S R_{\text {site }}(\mathrm{km})$, calculated as (van der Goot 1997):

$$
S R_{\text {site }}=D+W_{\text {alt }} \Delta_{\text {alt }}+\Delta_{\text {coast }}+\Delta_{\text {barrier }}
$$

where $D$ is the distance between the weather station and the grid-cell centre $(\mathrm{km}) ; \Delta_{\text {alt }}$ is the absolute difference $(\mathrm{m})$ between the site and grid-cell altitude; $W_{\text {alt }}=0.5$ is a weighting factor $\left(\mathrm{km} \mathrm{m}^{-1}\right) ; \Delta_{\text {coast }}$ is 
the absolute difference in corrected distance to coast $(\mathrm{km})$; and $\Delta_{\text {barrier }}$ is the climate barrier increment $(\mathrm{km})$. If a test ECA site is situated in a grid-cell with a complex terrain, we can potentially expect larger differences in statistics between ECA-observed and ELPIS-generated precipitation. To illustrate this, we investigated 4 ECA sites where differences in altitudes and precipitation bias were large: SID02006 in Germany, DU-E in the UK, SID00232 in Spain and SID00243 in Switzerland. Table S1 (in the supplement, www.int-res.com/articles/suppl/c057p001_ supp.pdf) shows site characteristics including differences in altitude and precipitation bias. In Fig. 3, the location of the SID02006 site is shown in the background of the digital elevation map overlaid with the ELPIS $25 \mathrm{~km}$ grid and the agricultural land mask. As seen in this figure, SID02006 is situated in a grid with relatively complex terrain and very little agricultural land. The SID02006 site is almost at the highest point in the grid-cell with a difference in altitude from the CGMS grid-cell of $765 \mathrm{~m}$, which adds, according to Eq. (1), $382.5 \mathrm{~km}$ to its site score $S R_{\text {site. }}$ Given the land
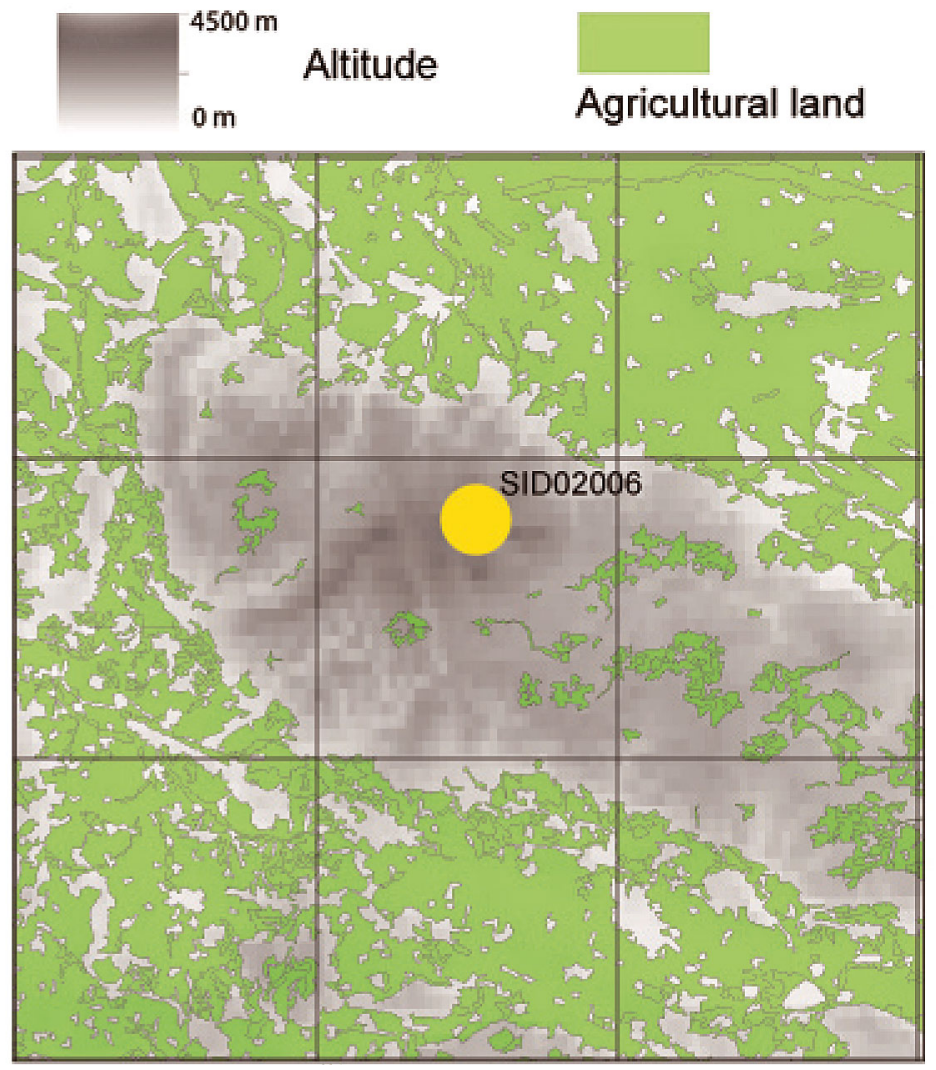

Fig. 3. Location of the SID02006 site (yellow circle) on the digital elevation map (darker grey shades correspond to higher altitudes) overlaid with the ELPIS $25 \mathrm{~km}$ grid. Green areas represent agricultural land. The difference in altitude between SID02006 and the corresponding ELPIS grid is $765 \mathrm{~m}$, and precipitation bias is $91.5 \mathrm{~mm}$ use characteristics, it is most unlikely that SID02006 could have been selected as representative of precipitation for this grid-cell. It is more likely that precipitation for this grid-cell would be assigned from a site situated within one of the neighbouring grid-cells that are predominantly used as agricultural land (Fig. 3). This could explain a precipitation bias of $91.5 \mathrm{~mm}$ between SID02006 and a corresponding ELPIS grid-cell. Similar reasoning could explain precipitation biases for 3 other sites (see Table S1, Fig. S5 in the supplement).

\subsection{Analysis of temperature}

There is a well-known relationship between air temperature and altitude, with an approximate $0.65^{\circ} \mathrm{C}$ temperature decrease per $100 \mathrm{~m}$ increase in altitude up to about $10 \mathrm{~km}$, reflecting the moist adiabatic lapse rate of the standard atmosphere (Wallace \& Hobbs 2006). Consequently, we can expect that the difference in altitude between an ECA site and an ELPIS grid-cell could result in a noticeable difference in maximum and minimum temperatures. Fig. 2C,D shows bias for minimum and maximum temperature and altitude differences for those sites where tests for temperature bias were significant. Temperature bias was significant at 51\% of sites for maximum temperature and $58 \%$ for minimum temperature. As expected, temperature biases were negatively correlated with altitude difference, decreasing by 0.42 and $0.68^{\circ} \mathrm{C}$ per $100 \mathrm{~m}$ for minimum and maximum temperature, respectively (Fig. 4C,D), Maximum temperature bias was better correlated with altitude difference with $\mathrm{R}^{2}=0.96\left(\mathrm{R}^{2}=0.69\right.$ for minimum temperature bias). The KS-test showed significant results only for those sites where temperature bias was significant and exceeded $2-3^{\circ} \mathrm{C}$ (at approximately $8.8 \%$ of sites with significant bias results). The $t$-test for monthly mean temperatures was more sensitive: $50 \%$ of sites with significant temperature bias for maximum temperature and $61 \%$ for minimum temperature showed $>3$ significant $t$-test results. Nevertheless, for the majority of these sites $t$-test results can be explained by differences in altitude between a site and a grid-cell. The number of sites with the exact number of significant results for $t$-tests and values of temperature biases for maximum and minimum temperature are shown in the supplement (Figs. S2 \& S3, respectively). 

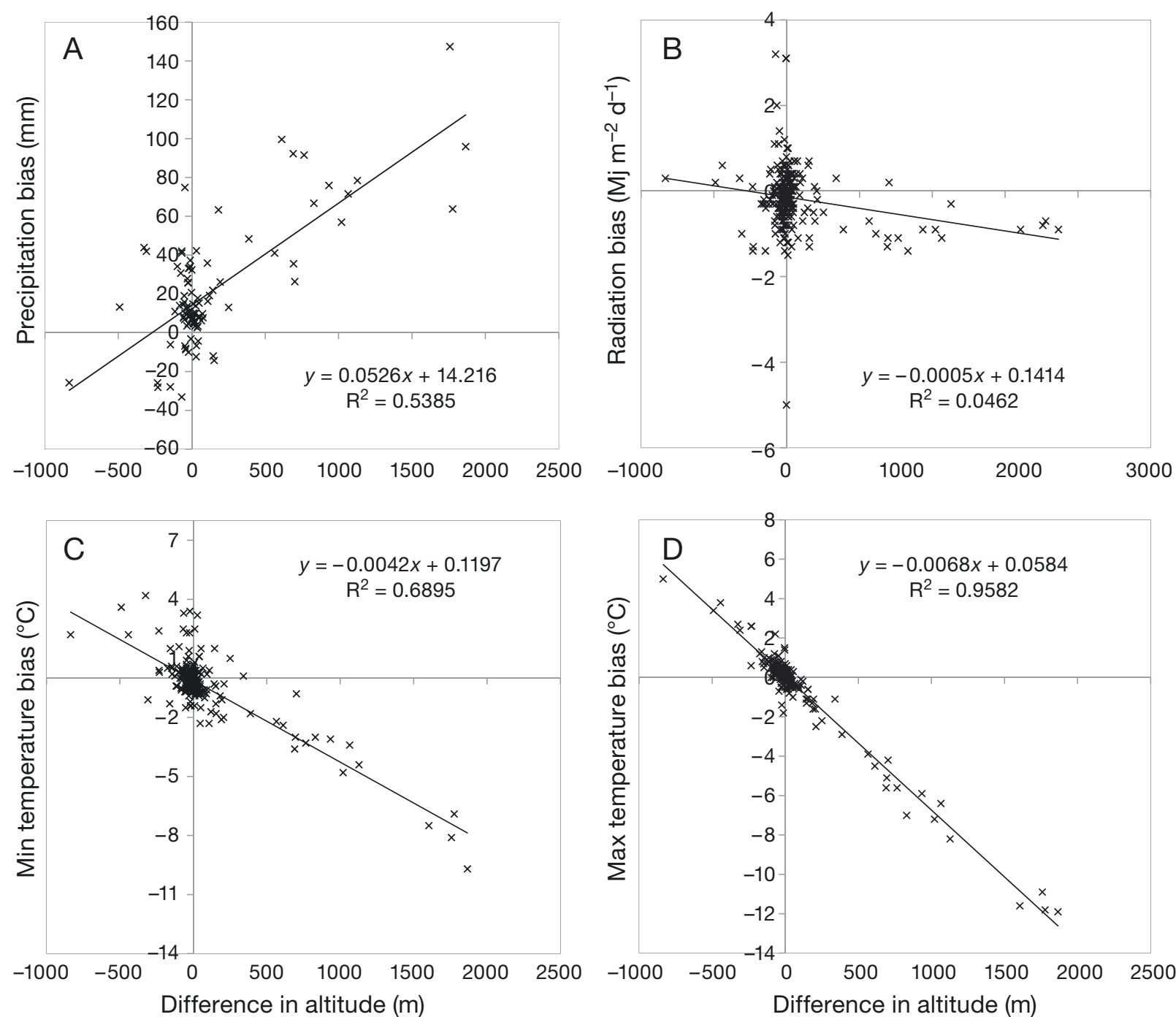

Fig. 4. Regression relationships between differences in altitude and (A) precipitation bias, (B) solar radiation bias, and (C) minimum and (D) maximum temperature biases between an ECA site and a corresponding ELPIS grid-cell. Only sites where tests for biases had significant results are shown

\subsection{Analysis of solar radiation}

Daily solar radiation was estimated from sunshine hours in CGMS using Supit's equation (Supit \& Van Kappel 1998) and for ECA sites using the equation from Rietveld (1978). Because of high variability of solar radiation, only 4 sites showed more than 3 significant results for the KS-test. Solar radiation bias showed little correlation with altitude difference (Fig. 4B), and only at 29 sites was the bias significant and exceeding a threshold of $1 \mathrm{MJ} \mathrm{m}^{-2} \mathrm{~d}^{-1}$ (Table 1 , Fig. S4 in the supplement). However, the number of sites where the $t$-test showed $>3$ significant results was very high: $225(90 \%)$. This could be explained by the different methods used to estimate solar radiation in the CGMS and ECA data sets. A quick comparison of 2 methods to estimate solar radiation at a single site, SID00239 in Switzerland, showed that the Supit \& Van Kappel method slightly overestimates observed solar radiation, and the Rietveld method underestimates observed solar radiation (Fig. S6 in the supplement). Different methods in estimation of solar radiation in the CGMS and ECA data sets could explain why $30 \%$ of sites have significant results for the solar radiation bias tests. However, the biases were relatively small for the majority of sites and did not exceed $1 \mathrm{MJ} \mathrm{m}^{-2} \mathrm{~d}^{-1}$ (Fig. S4 in the Supplement).

There might be another factor contributing to a large number of significant $t$-test results for solar radiation. The number of sites where observed sunshine hours were available for interpolation in CGMS was substantially less than the number of 
sites with observed temperature and precipitation. According to the CGMS interpolation procedure, several observed CGMS sites (up to 4) with the lowest score (see Eq. 1) were averaged to estimate solar radiation for a grid-cell. These sites could be far apart, which could result in smoothing the annual cycle for interpolated solar radiation, with slightly decreased summer peaks and increased values of solar radiation during winter compared with the ECA-observed values. Fig. 5 presents 30 -yr mean values for daily solar radiation for the ECA site (SID0416) and the corresponding ELPIS grid-cell. The bias test for solar radiation at this site showed no significant result, but the $t$-test for monthly means showed 10 significant results. In ELPIS-generated weather, solar radiation was higher during winter and lower during summer compared with solar radiation estimated for the SID0416 site (Fig. 5). The $t$-test picked up these differences for individual months, but the bias test for radiation showed no significant differences because differences in monthly mean solar radiation during summer have been compensated for by differences during winter.

\section{CONCLUSIONS}

Table 1 summarises the results of statistical tests comparing ECA-observed and ELPIS-generated baseline weather. Daily $25 \mathrm{~km}$ gridded climatic variables in the CGMS dataset were interpolated from observed site records using one (for precipitation) or several (for temperature and solar radiation) sites that

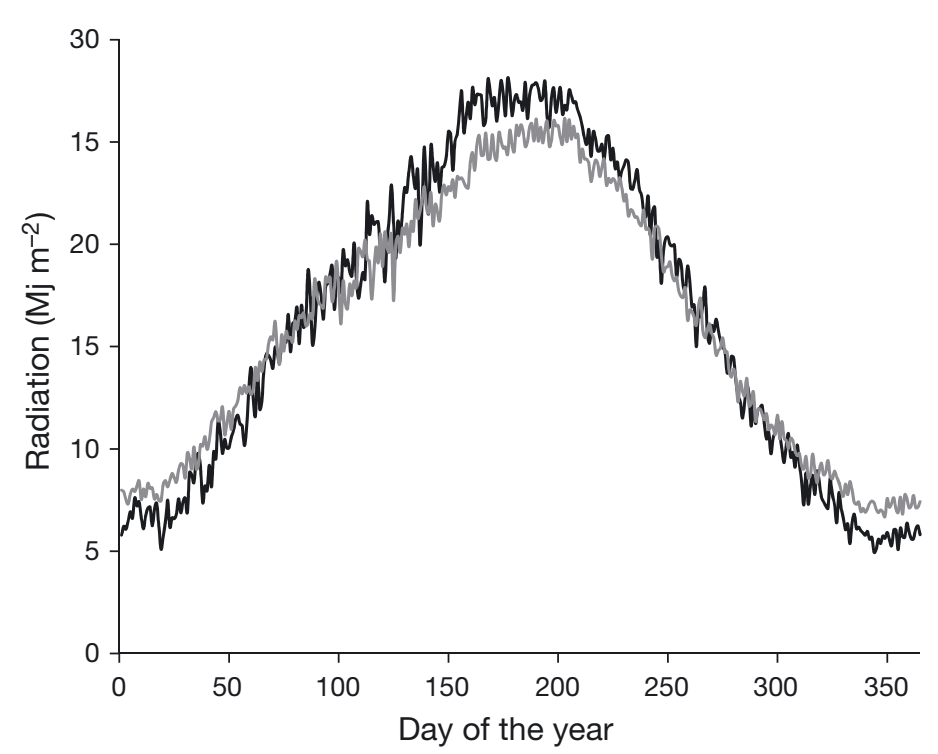

Fig. 5. Mean daily solar radiation for the ECA SID0416 site (black line), and the corresponding ELPIS grid-cell (grey line) have the minimum scores $S R_{\text {site }}$ defined by Eq. (1). During interpolation, heavy penalties were added to the site score $S R_{\text {site }}$ for the sites with large differences between site and grid-cell altitudes. In CGMS, the grid-cell altitude was selected to represent agricultural land only, even when the proportion of agricultural land in the grid-cell was relatively small. The number of ECA sites where the altitude difference between a CGMS grid-cell and a corresponding ELPIS grid-cell exceeded $50 \mathrm{~m}$ was $88(33 \%)$. We were able to explain the majority of significant statistical test results for precipitation and temperatures by these differences in altitude. The number of sites where the KS-test showed $>3$ significant results for precipitation and wet and dry series was 0 ; for minimum and maximum temperature it was 17 and 19 sites, respectively, and for solar radiation it was 4 (Table 1). The $t$-test was much more sensitive in detecting significant results in monthly means. Temperature bias was well correlated with altitude difference (Fig. 5), which could explained the large number of sites with significant results for the bias test when bias exceeded the $0.6 \mathrm{C}^{\circ}$ threshold: 77 sites for minimum and 59 sites for maximum temperature, respectively. Precipitation bias was less correlated with altitude difference (Fig. 4A), and only 65 site test results, where bias exceeded the $10 \mathrm{~mm}$ threshold, were significant. The bias for solar radiation, which exceeded the $1 \mathrm{MJ} \mathrm{m}^{-2}$ $\mathrm{d}^{-1}$, was significant only at 29 sites, although the number of sites with $>3$ significant $t$-test results was very high. This can be explained by different equations being used to estimate solar radiation from sunshine hours used in CGMS and for the ECA sites.

We can conclude that, for agricultural impact assessments in Europe, ELPIS baseline scenarios are suitable, considering the limitations described above. However, we would recommend running additional statistical tests to compare impact indexes computed by impact models using observed and ELPIS-generated daily weather time series to ensure applicability of ELPIS-generated climate scenarios for individual case studies. If ELPIS-based climate scenarios are needed for locations outside of agricultural land, then substantial differences can arise compared with climate scenarios derived using other downscaling techniques.

Acknowledgements. The research leading to these results has received funding from the European Union's Seventh Framework Programme (FP7/20072013) under grant agreements 282687 (Atopica) and 289842 (ADAPTAWHEAT). M.A.S. acknowledges sup- 
port from the international research project 'FACCE MACSUR - Modelling European Agriculture with Climate Change for Food Security, a FACCE JPI knowledge hub'. P.C. is grateful to the National Centre of Competence in Research on Climate (NCCR Climate), and the National Research Programme 'Sustainable Water Management' (NRP 61) for support. Rothamsted Research receives strategic funding from the Biotechnology and Biological Sciences Research Council of the UK.

\section{LITERATURE CITED}

Annan JD, Hargreaves JC (2010) Reliability of the CMIP3 ensemble. Geophys Res Lett 37: L02703 doi: 10.1029/ 2009GL041994

Barrow EM, Semenov MA (1995) Climate change scenarios with high spatial and temporal resolution for agricultural applications. Forestry 68:349-360

Calanca P, Semenov MA (2012) Local-scale climate scenarios for impact studies and risk assessments: integration of early 21st century ENSEMBLES projections into the ELPIS database. Theor Appl Climatol, doi: 10.1007/s00704012-0799-3

Eden JM, Widmann M, Grawe D, Rast S (2012) Skill, correction, and downscaling of GCM-simulated precipitation. J Clim 25:3970-3984

> Flaounas E, Drobinski P, Borga M, Calvet JC and others (2012) Assessment of gridded observations used for climate model validation in the Mediterranean region: the HyMeX and MED-CORDEX framework. Environ Res Lett 7:024017

> Fowler HJ, Blenkinsop S, Tebaldi C (2007) Linking climate change modelling to impacts studies: recent advances in downscaling techniques for hydrological modelling. Int J Climatol 27:1547-1578

Haris AA, Khan MA, Chhabra V, Biswas S, Pratap A (2010) Evaluation of LARS-WG for generating long term data for assessment of climate change impact in Bihar. J Agrometeorol 12:198-201

> Iizumi T, Nishimori M, Yokozawa M (2010) Diagnostics of climate model biases in summer temperature and warmseason insolation for the simulation of regional paddy rice yield in Japan. J Appl Meteorol Climatol 49:574-591

Iizumi T, Semenov MA, Nishimori M, Ishigooka Y, Kuwagata T (2012a) ELPIS-JP: a dataset of local-scale daily climate change scenarios for Japan. Philos Trans R Soc A 370:1121-1139

Iizumi T, Takayabu I, Dairaku K, Kusaka H and others (2012b) Future change of daily precipitation indices in Japan: a stochastic weather generator-based bootstrap approach to provide probabilistic climate information. J Geophys Res 117:D11114, doi:10.1029/2011JD017197

Kapphan I, Calanca P, Holzkaemper A (2012) Climate change, weather insurance design and hedging effectiveness. Geneva Pap Risk Insur Issues Pract 37:286-317

Klein Tank AMG, Wijngaard JB, Können GP, Böhm R and others (2002) Daily dataset of 20th-century surface air temperature and precipitation series for the European Climate Assessment. Int J Climatol 22:1441-1453

Klok EJ, Klein Tank AMG (2009) Updated and extended European dataset of daily climate observations. Int $\mathrm{J}$ Climatol 29:1182

Knutti R (2008) Should we believe model predictions of future climate change? Philos Trans R Soc A 366:4647-4664
Lazzarotto P, Calanca P, Semenov M, Fuhrer J (2010) Transient responses to increasing $\mathrm{CO}_{2}$ and climate change in an unfertilized grass-clover sward. Clim Res 41:221-232

Luo Q, Yu Q (2012) Developing higher resolution climate change scenarios for agricultural risk assessment: progress, challenges and prospects. Int J Biometeorol 56: 557-568

Maraun D, Wetterhall F, Ireson AM, Chandler RE and others (2010) Precipitation downscaling under climate change: recent developments to bridge the gap between dynamical models and the end user. Rev Geophys 48:RG3003

Meehl GA, Covey C, Delworth T, Latif M and others (2007) The WCRP CMIP3 multi-model dataset: a new era in climate change research. Bull Am Meteorol Soc 88:1383-1394

Qian BD, Gameda S, Hayhoe H, De Jong R, Bootsma A (2004) Comparison of LARS-WG and AAFC-WG stochastic weather generators for diverse Canadian climates. Clim Res 26:175-191

Qian B, Gameda S, Hayhoe H (2008) Performance of stochastic weather generators LARS-WG and AAFC-WG for reproducing daily extremes of diverse Canadian climates. Clim Res 37:17-33

> Rietveld MR (1978) A new method for the estimating the regression coefficients in the formula relating solar radiation to sunshine. Agric For Meteorol 19:243-252

Semenov MA (2008) Simulation of extreme weather events by a stochastic weather generator. Clim Res 35:203-212

Semenov MA, Stratonovitch P (2010) The use of multi-model ensembles from global climate models for assessment of climate change impacts. Clim Res 41:1-14

- Semenov MA, Brooks RJ, Barrow EM, Richardson CW (1998) Comparison of the WGEN and LARS-WG stochastic weather generators in diverse climates. Clim Res 10:95-107

Semenov MA, Donatelli M, Stratonovitch P, Chatzidaki E, Baruth B (2010) ELPIS: a dataset of local-scale daily climate scenarios for Europe. Clim Res 44:3-15

Street RB, Steynor A, Bowyer P, Humphrey K (2009) Delivering and using the UK climate projections 2009. Weather 64:227-231

Supit I, Van Kappel RR (1998) A simple method to estimate global radiation. Sol Energy 63:147-160

> van den Besselaar EJM, Klein Tank AMG, van der Schrier G, Jones PD (2012) Synoptic messages to extend climate data records. J Geophys Res D Atmospheres 117:D07101, doi: 10.1029/2011JD016687

van der Goot E (1997) Technical description of interpolation and processing of meteorological data in CGMS. EC Joint Research Centre, Ispra

van der Linden P, Mitchell JFB (2009) ENSEMBLES: climate change and its impacts. Summary of research and results from the ENSEMBLES project. Met Office Hadley Centre, Exeter

Wallace JM, Hobbs PV (2006) Atmospheric science. Elsevier Academic Press, Amsterdam

> White JW, Hoogenboom G, Kimball BA, Wall GW (2011) Methodologies for simulating impacts of climate change on crop production. Field Crops Res 124:357-368

Wilby RL, Wigley TML, Conway D, Jones PD, Hewiston BC, Main J, Wilks DS (1998) Statistical downscaling of general circulation model output: a comparison of methods. Water Resour Res 34:2995-3008

> Wilks DS (1992) Adapting stochastic weather generation algorithms for climate changes studies. Clim Change 22: $67-84$ 